\title{
O Big Brother Brasil e as formas contemporâneas de subjetividade
}

\author{
Bernardo Jablonski' e Erika L. Lazary²
}

\section{RESUMO}

Hoje em dia, aparecer na televisão pode reconfigurar o significado da própria existência (para si mesmo e para os outros). Talvez por isso, ser o foco dos olhares tenha virado uma prioridade de muitos, sendo quase como um emprego: uma forma de ganhar dinheiro, alcançar a tão almejada fama e virar uma celebridade. Neste estudo, analisamos alguns aspectos de um reality show, o Big Brother Brasil, tentando buscar um significado para sua tamanha repercussão social e construir possiveis elos que nos indicassem o caminho para responder uma de nossas questões principais: "Por que o BBB faz tanto sucesso?" Em nossa análise exploratória, através de uma perspectiva semiológica, supomos que sua fórmula do sucesso tenha se dado ao unir o útil ao agradável, tornando o privado, público e, ainda, garantindo a satisfação da curiosidade sobre a intimidade alheia. O Big Brother Brasil vem mostrar que todos têm chance, e estimula a possibilidade de concretização deste sonho ao convocar pessoas comuns e anônimas para fazer parte de seu cenário em troca do confinamento por alguns meses e da exposição estereotipada de diversos comportamentos.

Palavras-chave: televisão, subjetividade, espetáculo.

\section{ABSTRACT}

Nowdays, appear on a television show could change the meaning of one's own existence (to one's self and to others). That is maybe the reason why to be the focus of viewers has become a priority of many, becoming almost a job, a way to make money, to reach the aspiration of fame and become a celebrity. This study analyses some aspects of a reality show, the Big Brother Brazil, trying to figure out the meaning of its great social repercussion and construct possible links that would indicate a path to answer one of its main questions: "Why is BBB such a hit? "In our exploratory analysis, tough an semiological perspective, we believe that the success formula of this show is that it unites pleasure and gain, turning the private public, while satisfying the curiosity about other's intimacy. Big Brother Brazil came to demonstrate that anyone has a chance, and stimulates the possibility of achieving this dream by calling upon common anonymous people to be part of its scenery in exchange to being confined for a few months and exposed in diverse typecast behaviors.

Key words: television, subjectivity, show.

\footnotetext{
' Bernardo Jablonski foi professor do Departamento de Comunicação Social da UE.R.J e, atualmente. leciona no PPGPC da PUC-Rio.

'Érika Lazary è mestre em psicologia social pela PUC-Rio.
} 
"Em nosso mundo, quando todos somos filhos da televisão, pensar em viver sem ela como aparelho, ruído, instituição cultural, dispositivo de estórias, é impossivel. Cada dia fica mais difícil poder viver sem ela. Quase todos somos filhos da televisão, somos os programas que vemos e que gostamos."

Martin-Barbero

\section{Introdução}

Com o passar do tempo, a televisão tornou-se fundamental no processo de comunicação social, principalmente, por ser um veículo que alcança os telespectadores de maneira homogênea, ou seja, sem distinção de idade, sexo, raça ou classe econômica, permitindo a todos o acesşo às mesmas informações. Como geradora de conversa social, de simbolismos dos mundos particulares e paralelos (e entre eles) a TV se converteu em necessidade básica da vida diária e, por isso mesmo, 184 afins.

Por razões distintas, a prevalência da televisão como um dispositivo de socialização fez dela alvo de muitos críticos e também de muitos admiradores. Eco (1970) descreve estes dois grupos opostos em seu livro Apocalípticos e Integrados, sendo os "integrados" os adeptos da idéia da televisão como um instrumento estimulador da imaginação ao mesmo tempo em que educa e informa. Em contrapartida, os "apocalípticos" a veriam como um divertimento evasivo que manipula os hábitos de quem a assiste, reforçando apenas a passividade em cada um. De acordo com o autor, ambas as propostas são extremas e reduzem a dimensão do fenômeno televisivo a qualificações de um contexto restrito. Entretanto, as abordagens aparentemente concordam em um ponto específico: a televisão influi na formação da consciência do espectador.

Alguns estudos demonstram o quão eficaz é o impacto dos programas televisionados, como os de Cashmore (1998), DeFleur \& Ball-Rokeach (1993), Martín-Barbero \& Rey (2001), Sodré (1984a, 1984 b e 2002) e Thompson (1998). Tais autores mostram que a televisão é capaz de reestruturar o modo de viver de cada um, ou seja, pode influenciar a forma de se vestir, divertir, consumir, pensar e emocionar. 
Cashmore (1998), por exemplo, afirma que a televisão é fascinante porque corporifica a cultura que representa, como se fosse uma espécie de "espelho" social refletor do sistema que a produz. Além de a TV funcionar como espelho, também é um elemento social transformador, pois apresenta assuntos que provavelmente serão percebidos de diversas formas pelos telespectadores e, por isso, suscitarão questionamentos específicos em cada indivíduo. Assim, se por um lado, a TV consegue orientar e educar, por outro, ela pode reforçar os sentimentos de insegurança e impotência em cada um, uma vez que instaura padrões - como o modelo ideal de beleza - nem sempre condizentes com a realidade, embora pareçam ser aceitos como verdade pela sociedade atual. Talvez, como uma forma de evitar essa instabilidade interna, várias pessoas procurem conforto apreciando (e deixando-se apreciar por) outras, confirmando a tendência comum de se comparar e avaliar a própria condição no contexto onde se está inserido (Festinger, 1954). Esta tendência parece estar contribuindo para intensificar a audiência de programas que filmam indivíduos comuns em diferentes situações de uma vida real, os chamados reality shows.

O presente trabalho se concentra na análise das características de um reality show, o Big Brother Brasil (BBB), e de sua repercussão, para tentar entender porque esta atração tem um índice de audiência tão elevado. É preciso frisar que não se trata aqui de julgar a qualidade de um programa, mas, de tentar perceber o tamanho de sua audiência como um sinal - diretamente proporcional - de algum tipo de interesse dos telespectadores. Isso significa que não importa se, por exemplo, um programa é instrutivo ou sobre fofocas, até porque o adequado para alguns, pode não o ser para outros. O interessante é entender que as pessoas escolhem assistir a determinadas programações por alguns motivos particulares, sejam eles relativos ao entretenimento ou à educação. Cada um vai significar aquele instante (ou o programa) de uma forma única.

Para um programa alcançar altos índices de audiência e fazer sucesso é preciso haver elementos nos quais o público se reconheça e/ ou projete suas expectativas e características pessoais. Neste sentido, os reality shows parecem satisfazer algumas necessidades psicológicas importantes: ao mesmo tempo em que promovem entretenimento, oferecem modelos de intimidade para os telespectadores observarem, compararem-se e verificarem o quanto se assemelham à própria 
intimidade. Além de causar impacto em quem assiste ao programa, também proporciona a satisfação de quem escolhe expor sua intimidade, pois terá sua imagem veiculada em proporções significativas. Talvez, com o intuito de encontrar a almejada aceitação social e, conseqüentemente, se sentir mais bem conceituados, muitos indivíduos tenham assumido como uma prioridade alcançar notoriedade em grande escala, tornar-se uma celebridade, fazendo o ato de aparecer no enquadramento televisivo adquirir um significado de existência legitimada ("estou na televisão, logo existo") para uma infinidade de espectadores. Uns observam, outros são observados e, de alguma maneira, todos são correspondidos. O programa Big Brother parece ser um exemplo perfeito deste intercâmbio, retirando alguns do anonimato em troca da exposição de suas intimidades, para o deleite dos telespectadores.

Assim, no presente trabalho, o BBB é tomado como objeto de análise para se pensar em alguns princípios hoje difundidos na sociedade brasileira, tais como a competição, a fama, a ascensão social, o poder, etc. Em outras palavras, buscamos, a partir de alguns aspectos do BBB, inferir ilações que justifiquem tamanha audiência televisiva e, assim entender um pouco melhor o panorama das atuais expectativas culturais socialmente compartilhadas.

Por ser um trabalho exploratório, investigatório, baseado em um processo de análise, decidimos utilizar contribuições de teóricos da Psicologia, da Comunicação e de diversos autores que abordam temáticas relativas aos meios de comunicação social - como Augras (1986), Cashmore (1998), DeFleur\&Ball-Rockeach (1993), Jablonski (1998), Rocha (1995), Sarlo (2000), Thompson (1998) e Watzlawick et al. (1998). Com isso, nos permitimos ampliar nosso enfoque, sem nos prendermos a um autor específico, uma vez que o tema é muito atual e relativamente ainda pouco estudado.

Pelo significado atribuído à televisão e pelo fato de o Big Brother Brasil ser um dos programas mais assistidos e comentados da atualidade, acreditamos estar contribuindo na identificação de algumas características da sociedade brasileira, ao mesmo tempo em que apresentamos questionamentos, com o objetivo de refletir sobre determinados aspectos de nossa cultura. 


\section{Big Brother Brasil: vendendo o sonho de ser famoso}

Há alguns anos, no reino do popular, costumava-se proclamar a seguinte frase a quem quisesse chamar a atenção: Quer aparecer? Então coloca uma melancia no pescoço!!!". Hoje em dia, nada melhor do que aparecer na televisão para ser o centro das atenções, a melancia eletrônica da atualidade. Se antes, o aparelho de TV era apenas admirado, agora se transformou "no objelo elogiado, no novo altar onde são reveladas verdades modernas, onde se documentam as novas maneiras de ser deuses..."(Martin-Barrero, 2002, p. 14).

Por isso mesmo, ser o foco dos olhares virou a prioridade de muitos, sendo quase como um emprego: uma forma de ganhar dinheiro, subir na vida, fazer o que chamariam de sucesso, ou se preferir, alcançar a tão almejada fama. As pessoas estariam a cada dia vivendo mais em função do olhar de outros, reproduzindo expectativas e consumindo ilusões para além do necessário. Talvez, por isso também, tanta necessidade de aparecer, se exibir e obter reconhecimento público, seja lá por que meios ou através de qualquer espécie de atitude. O importante não é ter somente os "15 minutos de fama", mas de preferência "nunca mais ser esquecido!".

Possivelmente esta demanda da população brasileira reforçou a audiência dos chamados "Reality Shows", que sugerem uma comparação com a vida real. Assim, o Big Brother Brasil (BBB) tem contado com a participação ativa da população durante todo o período de exibição do programa, inclusive na eleição do vencedor que alcança altos índices de audiência, tanto no canal aberto - quando exibido pela maior emissora do Brasil (Rede Globo de Televisão) - quanto em fechado - exibido pelo Multishow e Pay per View.

Inúmeras teorias psicológicas apontam para a tendência dos seres humanos de, em algum momento, recorrerem ao olhar alheio, para se certificarem de sua condição: se estão bem, bonitos; se são amáveis ou tolos, etc. Winnicott (1954) lançou a hipótese dos bebês se desenvolverem emocionalmente, inicialmente, pelo olhar e manejo maternos. Sartre (1943), em grande parte de suas obras, ressalta como as pessoas dependem do olhar dos outros para se constituírem, sentirem que existem. É como se se vissem a partir do olhar do outro sobre si mesmas. E Festinger (1954) também ressaltou a importância deste processo, na medida em que tendemos a nos avaliar constantemente quanto a nossas 
aptidões, atitudes e comportamentos. De modo geral, esta avaliação é levada a cabo através do cotejo com outras pessoas, sendo a escolha destas um ponto importante dentro da teoria: a tendência aqui é darmos preferência a pessoas similares a nós. Embora, por vezes possamos escolher como alvo de nossas comparações pessoas que se notabilizaram de alguma forma por seus comportamentos, e que são neste aspecto, por isso mesmo, superiores a nós (da mesma forma, quando nos sentimos "por baixo", podemos nos contrastar com pessoas inferiores a nós com relação a alguma potencialidade - saúde, esperteza, beleza - para nos sentirmos melhores). Cite-se também que a escolha de modelos superiores pode igualmente ser usada para estipularmos um padrão de excelência a ser alcançado. Por estranho que possa parecer, esta teoria prega simplesmente que para podermos saber quem somos nós "por dentro", é preciso que dirijamos nosso olhar para fora de nós (Rodrigues et al., 2000).

Pode-se dizer que isso tem tudo a ver com a incapacidade última de se viver em isolamento. Em qualquer espaço onde a cultura humana se faz presente, existe, ao menos, uma relação dual. Sob este aspecto também, as sociedades foram se formando e estabelecendo normas de convivência comuns baseadas em direitos e deveres. Historicamente, com a influência dos ideais calvinistas, destacada principalmente a partir do século XVI, o trabalho (prestação de serviço em troca de capital) passou a ser extremamente importante, a fim de propor ao sujeito reconhecimento como um cidadão que cumpre o contrato social. Ao longo do século XVIII - com o poder já muito ligado à prosperidade - 0 êxito individual costumava se dar sob a forma de "carreira"/profissão ou, no caso das mulheres, através de casamentos bem sucedidos, cujas bases familiares pudessem render uma posição social elevada.

Atualmente, talvez seja possível generalizar e dizer que o significado de "sucesso" também se alterou, passando a incluir a questão de se alcançar seus próprios objetivos, sua satisfação pessoal, embora para cada pessoa, em cada cultura e em determinado contexto, esta palavra possa variar de significado. E no presente momento as pessoas buscam a fama, sinônimo do "antigo sucesso". Desta maneira, fama significa ter uma imagem coletiva, ter um status social e ter êxito com a aceitação da sociedade. Em outras palavras, confunde-se fama com aceitação, como se o olhar do outro fosse o único termômetro da popularidade ou da rejeição pessoal. 
Para ser famoso, hoje em dia, basta simplesmente estar na mídia, ser visado na sociedade, particularmente, por meio da televisão, já que o enquadramento do aparelho televisivo é compreendido quase como um sinônimo de êxito. Se, no geral, os seres humanos tendem a procurar referenciais nos valores e costumes alheios e, de alguma maneira, o que aparece na televisão passa a ser uma forma de validação das normas de conduta, é coerente utilizar a mensagem transmitida como um modelo a ser de fato seguido.

As informações e o conhecimento, antes obtidos por meio da aprendizagem direta, dos contos infantis, da família ou da Igreja, hoje são trazidas em sua maior parte pela TV, que acaba por ocupar o "/ugar do suposto saber" e difunde, de modo soberano, maneiras de se comportar e assumir determinado papel na atual sociedade de consumo.

Com relação ao Big Brother, especificamente, foi cm 1994 que dois produtores de televisão na Holanda, Joop van den Ende e John De Mol, associaram-se e fundaram a Endemol. Esta companhia se expandiu rapidamente, tornando-se uma das maiores produtoras independentes de televisão do mundo, passando a criar e exportar vários formatos de programas (hoje em dia, cerca de 500 fazem parte de seu catálogo), desde gêneros, como seriados e programas de variedades, até os reality shows. A idéia de produzir um programa onde pessoas eram, voluntariamente, confinadas numa casa e filmadas durantc todo o periodo de permanência foi testada na Holanda em 1999 e superou as expectativas, com sucesso absoluto. Três anos mais tarde, cste formato chegou ao Brasil e após sete edições ainda mantém um alto nivel de receptividade do público.

Como a maioria dos programas televisivos atuais, uma das principais finalidades dos reality shows obviamente ć obter audiência. Para isso, uniu-se o útil ao agradável: tornar o privado, público e, ainda, garantir a satisfação da curiosidade sobre a intimidade alheia. O "Big Brother Brasil" pode ser considerado um exemplo perfeito deste intercâmbio, retirando do anonimato os "caça-fama" ou sonhadores em troca da exposição de suas intimidades, para o deleite dos telespectadores. Já no título "Grande Irmão", as idéias de cumplicidade, companheirismo, afetividade, lealdade e tudo o mais estão explicitadas, respondendo facilmente às necessidades das expectativas das audiências - bem diferentemente do sentido do termo original referido ao romance de George Orwell. A intenção é proporcionar a identificação entre as 
histórias contadas e uma massa significativa de telespectadores através do estabelecimento de vínculos emocionais entre o público e os participantes do programa. Lembre-se que, apesar do que muitos pensam, o título Big Brother nada tem a ver com o famoso romance de Orwell, 1984, sobre um estado autoritário que procurava controlar toda uma população através de televisores/câmeras instalados dentro das casas das pessoas.

Com relação aos procedimentos típicos do programa, temos que, segundo as coordenadas do site oficial (www.globo.com/bbb):

"O prêmio de R\$ 1 milhão do Big Brother Brasil é disputado por 16 participantes - oito homens e oito mulheres - que ficam confinados na casa, completamente isolados do mundo exterior, e têm todos os seus passos vigiados por câmeras, 24 horas por dia. Serão ao todo 85 dias de confinamento para quem conseguir chegar à grande final... Durante esse tempo, o grupo está proibido de fazer ligações telefônicas, manter correspondência (por carta ou e-mail), assistir à televisão, ouvir rádio ou ler jornais e revistas. Os concorrentes mantêm contato apenas com o apresentador Pedro Bial, através da televisão instalada na sala da casa. Além disso, os BBs também podem receber a visita de alguns convidados, como artistas e apresentadores da Rede Globo."

O perfil desta montagem privilegia o espetáculo com conteúdos da realidade. A sedução do telespectador se dá logo de início, quando lhe é apresentado o local onde os participantes ficarão. A casa não é qualquer casa, é A CASA dos sonhos de qualquer cidadão (com jardim, piscina, cozinha bem equipada, banheira com hidromassagem...) e considerando que no Brasil a sua maioria tem uma condição de vida bem menos favorável, o sonho torna-se ainda mais sonho.

Já lá dentro, os eleitos para tentarem a fama seguem alguns scripts, que vão desde a realização das atividades mais simples do diaa-dia, como por exemplo, acordar, escovar os dentes, comer, se vestir, não fazer nada, discutir, conversar, dormir, etc., até competições pelo alimento da semana e a disputa pelo cargo de "líder" (que passa a deter, naquela semana, algumas regalias, tais como: ter a imunidade, dormir no quarto mais confortável, ver filmes, entre outras). Estas se tornam as aventuras mais significativas que poderiam ter em dois meses e meio 
aproximadamente. E claro, todo esse sacrificio merece uma recompensa: freqüentemente os participantes têm direito durante a estada na casa a "festinhas" com temas especificos, onde são promovidos festivais de bebedeira, azaração e muita diversão.

Obviamente, durante a transmissão do programa, os personagens são expostos aos olhares da grande massa e, semanalmentc, irão disputar a conquista do telespectador, a fim de permanecer na casa. Numa entrevista concedida à Revista Época (01/12/2003), Schouwenaar presidente da empresa que lançou o formato Big Brother $\mathrm{em} 22$ paises - dá alguns conselhos:

"para ganhar é preciso tocar o sentimento das pessoas. É um jogo. Alguns entram para jogar mesmo, o que é importante, já que é dificil manter-se na casa pelos três meses. Outros são manipuladores das emoções dos colegas. Num primeiro momento, eles são populares porque parecem mais hábeis, mas depois tudo muda. Em geral, os vencedores do BB são os mais naturais, os que realmente cativam o público. Na maioria homens, mas nem sempre."

Superficialmente, pode-se pensar que este programa exercita a capacidade crítica do público, uma vez que este tem o dever de analisar e julgar os comportamentos dos integrantes da irmandade. Mas o que sobressai mesmo é a estética do BBB, sua "aparência" c seu aspecto lúdico, fazendo conviver o jogo de sedução e o caráter estratégico e competitivo. Pare este último, Deutsch, já em 1949, frisava que a intercomunicação de idéias, a coordenação de esforços, a amizade e o orgulho por pertencer a um grupo - e que são fundamentais para a sua harmonia e a eficácia -, podem simplesmente desaparecer, caso seus membros passem a ter de competir para a obtenção de objetivos mutuamente exclusivos. Além disso, a competição pode levar a uma insegurança pessoal (expectativas de hostilidade por parte de outros), que iria de encontro a um espirito de cooperação.

A competição dos personagens inseridos nesta realidade fabricada acaba por atropelar valores e éticas na busca por uma rápida notoriedade e por um prêmio de - como na última edição realizada cm 2007 - hum milhâo de reais para o vencedor. 


\section{Espelho, espelho meu... afinal, quem sou eu?!}

Apenas perguntar ao espelho não garante uma resposta, mas pode ser um bom começo para iniciar uma longa discussão em busca do autoconhecimento. A cada dia, mais e mais sujeitos deixam de pensar em si para olhar o outro, procurando fora de si os princípios para a formação de sua própria identidade. Desta maneira, cada um só consegue se perceber olhando o outro, identificando-se e projetando-se no outro, indicando que a referência interna vai se distanciando e, aos poucos, sendo perdida. Como se, por não haver uma auto-afirmação direta, fosse necessário um "espelho", uma referência externa com que se possa identificar.

Como o presente grupo social está fortemente apoiado na comunicação, parece que a mídia, principalmente a televisão, impôs-se como norteadora das novas regras de atitude, comportamentos e desejos dos consumidores. A TV adquire assim um significado de "espelho mutante" e, com poucos questionamentos, a sociedade prefere se ver nele, pois esta parece ser a maneira preferencial de olhar para a sua auto-imagem: através do outro.

As características dos programas são o reflexo do que o público quer ver e este, por sua vez, se transformará no reflexo do que é visto (do que se escolheu para ser visto) - por ter seu centro de referência externo. Todo esse processo envolve um mecanismo de sabotagem, que faz o "feitiço virar contra o feiticeiro": o que era para ser um auxiliar na formação do autoconceito passa a ser o seu principal esteio. Além disso, como na quase totalidade das propagandas, a maior parte das produções da TV geralmente aponta que você poderia estar melhor do que está. Para isso, são utilizados modelos belos fisicamente e pessoas famosas a fim de reproduzirem o ideal das pobres "criaturas" comuns. Num meio onde se é estimulado a ter tudo o tempo inteiro, as imagens de muita gente tendo tuido do bom e do melhor faz com que as pessoas da vida real se sintam em desvantagem e, obviamente, sequiosas por melhorias e avanços sociais.

É o que Eugen Buvcar, em seu documentário "Janela da Alma", quer dizer, em última análise, ao comentar que atualmente vivemos em um mundo que perdeu a visão. Isto é, que a televisão ao nos propor basicamente apenas imagens prontas, nos impede de vê-las, na medida em que, sem um necessário olhar interior, nada mais pode ser visto de 
verdade.

Este distanciamento de si mesmo - a fuga interna - é o que parece estimular e alimentar todo esse mecanismo de fama, glamour e "voyuerismo" buscado e consentido. Automaticamente, espera-se que se deixe a cargo do outro - ou melhor, da televisão - a responsabilidade sobre atitudes e emoções, deixando a comparação social no papel de carregar todo o peso da balança, pondo de lado o a introspecção e a autoconsciência.

$\mathrm{Na}$ verdade, pode-se dizer que fugir de si mesmo e ocupar-se com os detalhes da vida da celebridade vêm satisfazer duas necessidades psicológicas: buscar uma referência de valor através da comparação com o outro ("se ele que é ele está na mídia, eu também posso estar"); e também, concomitantemente, de fragmentar a figura de perfeição inalcançável dos famosos, trazendo-os para mais próximo de si. Isso cumpre a condição básica de se proteger de possiveis frustrações diante da perfeição do mito.

\section{Uma realidade de sonhos}

"... evidentemente, na medida em que os individuos pertencem ao mesmo grupo e portanto compartilham a educação, a lingua, a experiência e a cultura, temos boas razões para supor que suas sensações são as mesmas. Se não fosse assim, como poderiamos compreender a plenitude de sua comunicação e o caráter coletivo de suas respostas comportamentais ao meio ambiente? É preciso que vejam as coisas e processem os estimulos de maneira quase igual..." (Kuhn, 1969:239)

O meio ambiente fornece vários tipos de estímulos, embora os seres humanos não sejam capacitados para percebê-los integralmente até por uma questão adaptativa -, sendo necessária uma espécie de "triagem" do que é mais importante ou conveniente perceber.

Demócrito, quatrocentos anos antes de Cristo, já dizia: "Muita coisa perceptivel não é percebida por nós". O foco da atenção humana é variável de acordo com o grau de motivação da pessoa submetida àquele estímulo ou do quanto o estímulo é ligado à sobrevivência (Stingel e Portella, 1998). Além disso, pesquisas psicossociais comprovaram que padrões de conformidade são diretamente proporcionais ao nível de 
insegurança sentida (Jablonski, 1998:188).

Análises assim são relevantes, a nosso ver, na medida em que os programas de TV estão, cada vez mais, repletos de violência, banalidades e futilidades, que servem de (maus) guias para um público que nem sempre se dispõe a refletir criticamente acerca do conteúdo do que vê na TV. A sociedade se deixa aprisionar a um modelo onde a TV opera, com ou sem ética, pois independentemente dos conteúdos, para o sucesso de qualquer programação é necessário responder ao olhar do telespectador. Entretanto, isso não significa, evidentemente, que esta invenção tecnológica seja um "mal social".

O problema, é claro, não é a televisão, mas a forma como suas imagens geralmente são capturadas e confundidas com a realidade. Bachelard (apud Simões, 1999:20) assinalou que "pensar corretamente o real é aproveitar suas ambigüidades para modificar e alertar o pensamento", sendo sempre necessária a interpretação racional para colocar os fatos em seu lugar apropriado.

Contudo, a sociedade contemporânea parece ter perdido o interesse por reflexões complexas e talvez seja mesmo difícil interpretar as 194 sensações que estão à disposição para uma análise aprofundada do que lhe é dado. Se por um lado, o receptor opta por determinado tipo de programação que, de uma forma ou de outra, o atrai e com a qual se identifica, por outro, grande parte da população está se deixando manipular, por não se sentir segura para seguir caminhos diferentes. $\mathrm{O}$ fato é que, por estarmos vivendo em uma época em que as transições são bruscas, em que reina uma boa dose de instabilidade e em que se presencia uma rejeição de velhos valores sem que os novos estejam ainda devidamente assentados e reconhecidos, nos vemos obrigados a conviver com um aumento generalizado do grau de insegurança. Deste modo, a maior parte dos telespectadores parece não querer mais pensar por si mesma: devido à tamanha insegurança em desvendar novos horizontes, as pessoas preferem que façam isso por elas, buscando apenas um modelo a ser seguido, ou de preferência, informações que indiquem o melhor caminho de ser.

Quem se encarrega disso são os meios de comunicação, sendo a televisão a maior responsável por transmitir as informações atuais e as "verdades" que nortearão as expectativas e o comportamento de toda uma sociedade imobilizada e estanque. Tamanha identificação das pessoas talvez se dê na medida em que a maior parte delas se sinta 
numa condição semelhante ou tenha um nivel de aspiração baixo e, para se sentir melhor do que está, prefere assistir a programas assim. De fato, para um programa alcançar altos niveis de audiência e fazer sucesso é preciso algum elemento de identificação com o público. No caso em questão, do BBB, a transformação da vida num veículo de entretenimento não poderia ter dado mais certo.

Aparentemente os reality shows vêem justamente preencher a lacuna da demanda social por uma permanente diversão fácil. Sem maiores esforços, anônimos no conforto de seus lares observam atentamente cada aspecto da "intimidade controlada" dos que buscam a fama - antes pessoas comuns, mas agora, celebridades. Além de satisfazer toda a curiosidade ansiosa por comparação, os tclespectadores ainda "adquirem o poder" para decidir o futuro dos participantes e continuarem protegidos pela tela de um computador ou um telefonema que, além de receber atendimento digital, muitas vezes é pago. O BBB, ao mesmo tempo em que permite aos telespectadores "voltar a ser criança", os convida a fazer parte de um jogo no qual algumas atitudes reprimidas socialmente são não só plausíveis como estimuladas. Em contrapartida, os participantes que se comportam de maneira semelhante aos telespectadores são julgados e punidos. Em outras palavras, aquele participante que tem um bom relacionamento com os demais na Casa, ou aquele que é estrategista, ou aquele que fofoca, ou aquela que fica muito tempo na piscina, ou ainda o que assume ser homossexual, todos, de alguma maneira, se transformam em jogadores de um jogo onde não se deve jogar. Por isso também o BBB se revela um jogo baseado em contradições que o sustentam. Por trás de todo este caráter estratégico e competitivo, há a conversão do processo em um jogo de sedução e astúcia. Desta maneira, a competição dos personagens desta "realidade fabricada" pode atropelar valores e éticas da vida real na busca dos benefícios de uma notoriedade (mesmo que momentânea) e por um prêmio milionário para o vencedor.

\section{Você ainda não viu nada!}

Com esta sentença, inspirada na propaganda do Big Brother Brasil, finalizamos nossa parcela de contribuição, como um ponto de partida para a compreensão de muitas questões oriundas da relação entre os telespectadores e os reality shows. Procuramos analisar o 
referido programa acreditando que tamanho sucesso estaria relacionado com algumas atitudes e expectativas relevantes da sociedade contemporânea, e, certamente, foram criadas mais questões do que respostas. Não pretendíamos algo de muito diferente, na medida em que ainda precisamos de muito mais estudos para poder avançar significativamente no entendimento das relações entre o que faz sucesso na telinha e o que sonha o brasileiro para a sua própria realidade.

\section{Rereferências}

Barbero, J. M. in: Televisão Pública: do consumidor ao cidadão. São Paulo: Friedrich-Ebert-Stiftung, 2002.

Deutsch, M. (1949). A theory of co-operation and competitition. Human Relations, 2, 129-152.

Documentário: Janela da Alma. Roteiro e direção: João Jardim; Co-direção e fotografia: Walter Carvalho; Música: José Miguel Wisnik.

Fernandez, V. F. in: Televisão Pública: do consumidor ao cidadão. São Paulo: Friedrich-Ebert-Stiftung, 2002.

Festinger, L. (1954). A theory of social comparison processes. Human Relations, 7, 117-140.

Golçalves e Retat "O grande e os pequenos irmãos" in: Ciência Hoje. vol. 31. $n^{\circ} 183$. 1998.

Jablonski, B. Até que a vida nos separe. Rio de Janeiro: Agir,

Kuhn, T. A Estrutura das Revoluções Cientificas. São Paulo: Perspectiva, 1969.

Pereira, C. S. Adolescência por trás da midia: analisando Capricho e Friends, in: Psicologia Clínica: das novas configurações à violência familiar, vol.15.2 Rio de Janeiro: Companhia de Freud: 2003.

Pena, Felipe. Televisão e sociedade: do Big Brother à TV universitária.. Rio de Janeiro: Sette Letras. 2002.

Revista Época - "Espiar é humano". Edição 289 - 01/12/2003.

Revista Veja - "Mulheres apaixonadas e apaixonantes". Edição $1810-09 / 07 / 2003$.

Rodrigues; A., Assmar, E. e Jablonski, B. (2000). Psicologia social. 22a edição. Petrópolis: Vozes.

Sartre, J. P. O ser e o Nada. São Paulo: Vozes, 1943.

Simões, R. A Imaginação Material segundo Bachelard- 
Dissertação de Mestrado em Filosofia: janeiro/1999 - UERJ/IFCH; orientador:?

Stingel, A. M. e Portella, M. C. Processos cognitivos. Rio de Janeiro: Wilson e Wilton Cotrim, 1998.

Site (acesso em: 07/05/2004): www.teses.usp.br/teses/ disponiveis/8/8132/tde-25092003-171416/publico/bach2rita.pdf

Távola, A. A liberdade do ver: Televisão em leitura crítica. Rio de Janeiro: Nova Fronteira, 1984.

Vilhena e Medeiros "Midia e perversão" in: Ciência Hoje. vol. 31. $n^{\circ} 183$.

Winnicott, D. Natureza Humana. Rio de Janeiro: Imago, 1990. 
